\title{
Effect of The Incorporation of Micro and Nanoparticles of Calcium Carbonate in Poly (Vinyl Chloride) Matrix for Industrial Application
}

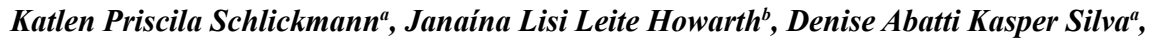 \\ Ana Paula Testa Pezzin ${ }^{a}$ (D) \\ a Programa de Pós-Graduação em Engenharia de Processos, Universidade da Região de Joinville \\ (Univille), Joinville, SC, Brasil \\ ${ }^{b}$ Centro Universitario Sociesc-UNISOCIESC, Joinville, SC, Brasil
}

Received: December 12, 2018; Revised: July 31, 2019; Accepted: August 15, 2019

\begin{abstract}
This study aimed at evaluating the effects of the incorporation of micro and nanoparticles of $\mathrm{CaCO}_{3}$ on the properties of poly(vinyl chloride) (PVC), intended to industrial application. The PVC compounds added with particles of different sizes were achieved in an intensive mixer. Rheological, microstructural, mechanical and thermal properties of the compounds obtained were evaluated. The rheology test showed that the compound with the addition of two-particle size plasticized faster compared than other formulations. Microstructural analysis showed a poor particle size distribution for the micro- $\mathrm{CaCO}_{3}$ charges, and the nano- $\mathrm{CaCO}_{3}$ samples have agglomerated particles. The thermal analysis showed the compound added with two particle size with higher gelation, and in the loss modulus E' and E", the values also were close. The analyses showed that the combination of the two-particle sizes presented superior results when compared with the micro or nano used singly.
\end{abstract}

Keywords: poly(vinyl chloride); calcium carbonate; nanocomposite, nanoscale filler, microscale filler

\section{Introduction}

Over the last years, organic-inorganic composites, especially nanocomposites, received a lot of attention because these materials could generate different properties. Several filling in nanoscale, including montmorillonite, silica, calcium carbonate $\left(\mathrm{CaCO}_{3}\right)$, and aluminum oxide, were studied to improve the mechanical and thermal properties of polymers, as tenacity, rigidity and thermal resistance. The mechanical properties of nanocomposites are highly dependent on the filling ratio, the surface area and the interaction between the fillings and the polymeric matrix. Loads with an aspect ratio relatively high, obviously did not improve the resistance, and sometimes can even reduce it. ${ }^{1}$

The low aspect ratio and the large spherical surface area makes mineral nanoparticles results in strong interactions between the filling and the polymeric matrix. The nano$\mathrm{CaCO}_{3}$ is one of the most used loads in the preparation of nanocomposites. The classes of $\mathrm{CaCO}_{3}$ can be based on different sizes distributions, size of the particle, surface area, morphology, surface treatment, and so on ${ }^{1}$.

The poly(vinyl chloride) (PVC) is a thermoplastic material used all around the world. The PVC is widely used to manufacture tubes, doors, windows, and others in the construction industry. The use of nanoparticles of calcium carbonate, not only improves the tenacity, electrical properties, heat resistance, radiation resistance and other properties, but also reduces the cost of the compounds.
The effects of the loads on the microstructure and on the properties of the PVC compounds depends strongly on the shape of the particle, size of the particle, aggregate size, surface treatment, the fraction of load e its dispersion grade. However, it's low stability against temperature and fragility can be a limiting factor in certain applications. Therefore, to extend the range of applications of PVC, it is necessary to develop new formulation to the compound of PVC using low-cost additives and with effective strategies of properties improvement $^{1,2}$.

The use of nanofillers has called the attention and interest from the academy and from the industry due to the different properties that nanoparticles show, being possible obtain materials with superior characteristics, when compared to compounds produced with microparticulated materials. In the nanotechnology universe, the nano-calcium carbonate (nano- $\mathrm{CaCO}_{3}$ ) proves itself as an interesting option to be added to rigid PVC compounds, aiming to improve the mechanical properties and the low cost of formulation ${ }^{3}$.

The effect of nano- $\mathrm{CaCO}_{3}$ on the mechanical properties of PVC has been studied by several authors ${ }^{1,4,5,6}$. In the studies of Jazi et al. (2012) ${ }^{7}$ it was reported that the impact resistance and Young's modulus were visibly improved with the addition of 5-25 phr (parts by weight per hundred parts of resin) of nano- $\mathrm{CaCO}_{3}$, but its elongation at break was reduced. The ideal content of nano- $\mathrm{CaCO}_{3}$ particles to improve impact resistance was about $15 \mathrm{phr}$ to $\mathrm{PVC}$ composites / nano- $\mathrm{CaCO}_{3}$. 
Wu et al. (2004) ${ }^{4}$ investigated the effect of chlorinated polyethylene as interfacial modification agent in PVC nanocomposites/nano- $\mathrm{CaCO}_{3}$. The mechanical properties, morphology and rheology of these materials were investigated. The average nanofiller size was $40 \mathrm{~nm}$. It could be observed a moderate toughening of the nanocomposites. The elongation at break and the Young's modulus also increased as the content of nanoparticles increased. The TEM study showed that nano- $\mathrm{CaCO}_{3}$ dispersed uniformly in the PVC matrix with some agglomerations. It could also be observed that the nano$\mathrm{CaCO}_{3}$ particles in the PVC matrix were encapsulated with a CPE layer through the preparation of nano- $\mathrm{CaCO}_{3} / \mathrm{PVC}$.

Patil et al. (2009) ${ }^{1}$ prepared PVC compounds with micro and nano- $\mathrm{CaCO}_{3}$ and characterized their mechanical and thermal properties. The x-ray diffractometry at high angle results (WAXD) and scanning electronic microscopy (SEM), confirmed that the load dispersion was not adequate in the PVC matrix and, therefore, the PVC nanocomposites structure was intercalated and flocculated. The tensile strength of both micro and nanocomposites reduced with the increased content of $\mathrm{CaCO}_{3}$. The storage module of both composites was slightly higher than the pure PVC. The glass transition temperature of both composites was also higher than pure PVC. In addition, the degradation temperature of composites with nano- $\mathrm{CaCO}_{3}$ was slightly higher than the microcomposite and pure PVC. So, the study showed that there was poor interaction and dispersion between PVC and the nano- $\mathrm{CaCO}_{3}$ load.

In this context, this study evaluated the effect of the addition of different percentages of micro- $\mathrm{CaCO}_{3}$ and nano- $\mathrm{CaCO}_{3}$ in PVC matrix over the rheological, thermal, morphological and mechanical properties.

\section{Experimental}

\subsection{Materials}

The PVC polymer used in this study was the SP 700 from Braskem ${ }^{\circledR}$. The $\mathrm{CaCO}_{3}$ used in micrometric scale was the Micron 1/2 CDL, of calcitic origin and coated with $1.2 \mathrm{wt} \%$ of stearic acid, donated by Micron-ita $\AA$. The $\mathrm{CaCO}_{3}$ used in nanometric scale was Socal 312, from the manufacturer Socal ${ }^{\circledR}$, this product consists of calcium carbonate precipitated with ultra-fine liner of $2.9 \mathrm{wt} \%$ of stearic acid.

\subsection{Incorporation of calcium carbonates in PVC compounds}

The $\mathrm{CaCO}_{3}$ in micro and nanoscales were incorporated in PVC resin for formulations specified, varying its concentrations. The formulation with chlorine impact modifiers was used, because it is the most used toughening in the industry nowadays. The formulations are in accordance to Table 1 with values in parts per hundred parts of resin (hpr), calculation of formulation, which is usually applied in the industry, fixing the resin as reference. For the incorporation of $\mathrm{CaCO}_{3}$ a mixer Mecanoplast model 11L92 $\mathrm{V}$ was used, with mixing capacity of $3 \mathrm{~kg}$. The mixing started with the equipment pre-heated at $90{ }^{\circ} \mathrm{C}$, raising the rotation to $1200 \mathrm{rpm}$ and final temperature of the mixture at $120^{\circ} \mathrm{C}$. The additives were weighted along with the resin and inserted in the mixer, at the same time, all components reached $120^{\circ} \mathrm{C}$, in the weighting sequence of the components of Table 1, thus, at the end of the mixture a powder PVC compound was obtained.

\subsection{Obtaining of specimens}

Firstly, the compound of formulations with micro and nano- $\mathrm{CaCO}_{3}$ were put in a calender Mecanoplast model $\mathrm{C} 4003$ at $190{ }^{\circ} \mathrm{C}$ for $3 \mathrm{~min}$, to obtaining sheets of PVC compound. These sheets were subsequently put in a press Mecanoplast model PRL-25 at $175{ }^{\circ} \mathrm{C}$, with molds in the shape of the specimens according to the ASTM D256-06 standard related to impact resistance and ASTM D628-2a related to tensile strength. The pressing time was $10 \mathrm{~min}, 6$ min with $60 \mathrm{kgf} / \mathrm{cm}^{2}$ pressure and $1 \mathrm{~min}$ with $150 \mathrm{kgf} / \mathrm{cm}^{2}$ total pressure. The specimen groove was performed, using milling machine equipment type Universal Vigoreli Model FU-33, and its angulation was according to the standard.

\subsection{Compound characterization of PVC with micro e nano calcium carbonate}

\subsubsection{Rheology Testing}

The rheology testing was performed by means of a touch rheometer Thermo Haake, according to ASTMD 2396 and ASTM D2538 standards. The purpose of the testing was analyzing the grade of plasticizing of the compounds and checking if this compound is processable in equipment in industrial scale.

Table 1. Formulation of the PVC compounds (hpr).

\begin{tabular}{|c|c|c|c|c|c|c|}
\hline Formulation components & F1-5M & F2-10M & F3-5N & F4-10N & F5-MOD & F6-5NM \\
\hline PVC Resin & 100 & 100 & 100 & 100 & 100 & 100 \\
\hline Micro- $\mathrm{CaCO}_{3}$ & 5 & 10 & 0 & 0 & 5 & 2.5 \\
\hline Nano- $\mathrm{CaCO}_{3}$ & 0 & 0 & 5 & 10 & 0 & 2.5 \\
\hline Flow auxiliary & 1 & 1 & 1 & 1 & 1 & 1 \\
\hline Stabilizing $\mathrm{Ca} / \mathrm{Zn}$ & 5 & 5 & 5 & 5 & 5 & 5 \\
\hline Acrylic impact modifier & 0 & 0 & 0 & 0 & 1 & 0 \\
\hline
\end{tabular}


An amount of $70 \mathrm{~g}$ of each PVC compound was inserted in the heating chamber at $160{ }^{\circ} \mathrm{C}$, being plasticized by rotors at $60 \mathrm{rpm}$, and the interruption of the testing occurred after the plasticizing curve obtained by the PVC compound. A sample of each formulation was analyzed, and F5-mod was analyzed 3 times to measuring the results, in this case the rheological curves are within the pattern stipulated.

\subsubsection{Microscopic Analysis}

The dispersion analysis and distribution of the nano-

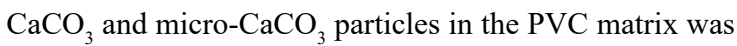
performed by means of SEM (JEOL, model JSM-6701F), under accelerating voltage of $15 \mathrm{kV}$ and magnification of 5000,7000 , and 9000x. The fractured samples surfaces have been analyzed after the impact test. The samples were covered with gold in an equipment Baltec 5CD 050 during $90 \mathrm{~s}$ and fixed on the microscope sample holder with a carbon tape.

To analyze the dispersion of nano and micro- $\mathrm{CaCO}_{3}$ particles in the PVC matrix, the samples have been cut using the crioultramicrotomy technique. Therefore, a ultramicrotome (Leica, model EM UC7), temperature at $-70{ }^{\circ} \mathrm{C}$ was used. Cuts have been made with a thickness of about $50 \mathrm{~nm}$, using a diamond knife Cryo Dry Ultramicrotomy of 4,5 mm, TedPella. The cuts were put in copper grids, 200 mesh, EMS. The samples were analyzed in a transmission electron microscope (TEM) (JEOL, model JEM 1200 EXII), using voltage of $80 \mathrm{kV}$.

\subsubsection{Mechanical Analysis}

The impact resistance test was performed with PVC compounds intended to evaluate if there would be synergy between the loads added and the matrix, related to tenacity. The tests were performed according to the ASTM 256 standard. Before the tests being carried out the samples were conditioned at a temperature of $23 \pm 2{ }^{\circ} \mathrm{C}$ and $50 \pm 5 \%$ relative humidity during $40 \mathrm{~h}$. The equipment used was the Ceast Resil and the specimen hammer was the $4 \mathrm{~J}$.

The tensile strength test was performed aiming to evaluate if there would be more tenacity of the compound treated with the loads added at the matrix. The test was performed according to the ASTM D638 2 a standard, with the specimens conditioned during $40 \mathrm{~h}$ at $23 \pm 2{ }^{\circ} \mathrm{C}$ and $50 \pm 5 \%$ relative humidity. The purpose of the test was to check the tensile strength, elongation at break and, Young's modulus at the nanocompound rupture compared to the microcompound. The equipment used was a universal test machine Instron 5581, the test speed was $50 \mathrm{~mm} / \mathrm{min}$ with the specimen rupture.

\subsubsection{Thermal Analysis}

The differential scanning calorimetry (DSC) curves was performed in all formulations in a TA Instruments equipment, model Q2000, according to ISO 18373-1. Around $20 \mathrm{mg}$ of the samples were heated at 40 to $250{ }^{\circ} \mathrm{C}$ to $25^{\circ} \mathrm{C} / \mathrm{min}$ under $\mathrm{N}_{2}$ atmosphere.
The degree of gelation is a very important parameter, as through its control, it will substantially influence the final product mechanical properties and the degree of gelation can be obtained by DSC through the both endothermic peaks $(\Delta \mathrm{Ha}$ e $\Delta \mathrm{Hb}$ ) using the equation 1 :

$$
\% G=\frac{\Delta H a}{\Delta H a+\Delta H b} \times 100
$$

The degree of gelation of the equation 1 mentioned, can be obtained through the endothermic peaks area of the PVC, according to Fig. 1. The value is obtained between the peaks T1 and T2, while is obtained between the peaks $\mathrm{T} 2$ and $\mathrm{T} 3$.

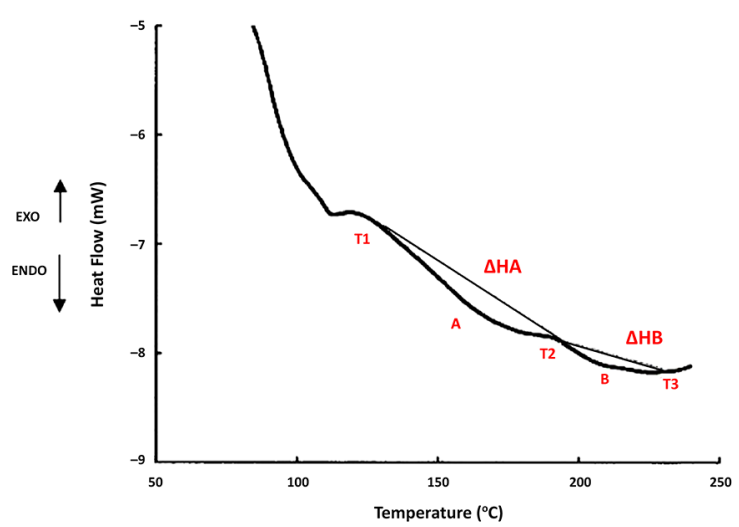

Figure 1. Obtention of $\Delta H a$ e $\Delta H b$ through the DSC graph.

The thermogravimetric analysis (TGA) was performed in all formulations in a TA Instruments TGA - Q50 equipment according to the ASTM E1131 standard. About $10 \mathrm{mg}$ of the samples have been heated at 40 to $1000{ }^{\circ} \mathrm{C}$ to $25^{\circ} \mathrm{C} /$ min under $\mathrm{N}_{2}$ atmosphere.

The dynamic mechanical analysis (DMA), was performed in a TA Instruments Q800 equipment according to the ASTM D4065 and E1640 standards using a single cantilever device. The samples have been heated at 0 to $150{ }^{\circ} \mathrm{C}$ to $2{ }^{\circ} \mathrm{C} / \mathrm{min}$ with a frequency of $1 \mathrm{~Hz}$ and amplitude of $100 \mu \mathrm{m}$ under $\mathrm{N}_{2}$ atmosphere.

\section{Results and Discussion}

\subsection{Rheological Properties}

To the plastic processing industry, with emphasis in PVC, it is necessary to evaluate the level of plasticizing of the PVC compound and how it will behave as regards the machinery torque (injectors, extruders). The conversion of PVC compounds in products, rigid and flexible, through transformation processes by molding are dependent on a phenomenon known as gelation of PVC resin. The gelation process of the PVC compound is carried out through application of shearing and temperature, process known as malaxation ${ }^{8}$. 
The degree of gelation is a very important parameter, as it will substantially influence the final product mechanical properties, that's because the unplasticized particles can become a fragility point in the final product, influencing the mechanical properties. In Fig. 2, the graphs obtained during the test are showed with the gelation curves characteristic of each formulation of micro and nano PVC compound.

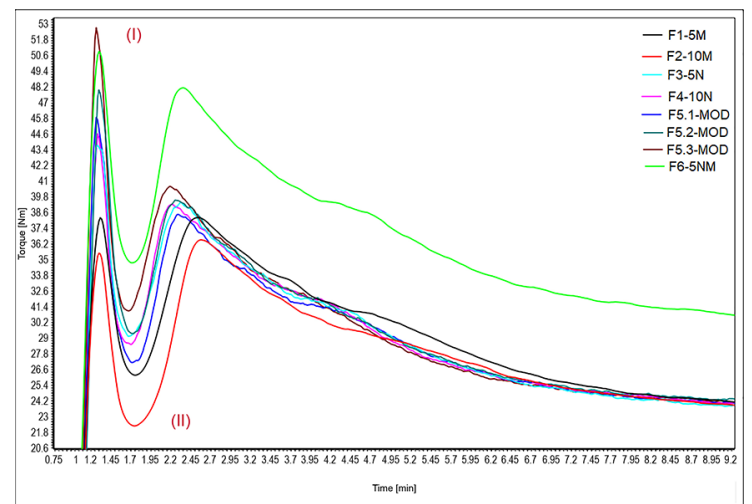

Figure 2. Gelation curve/melting of formulation from 1 to 6 .

The curves in Fig. 2 shows the connection between the torque and gelation time. Two specific peaks can be observed from the melting curve. The first peak means the loading of the sample (I). At this point, the torque starts to reduce due to the powder free flow. Then the torque starts increasing due to the compaction, melting and entanglement of molecules of PVC in a primary surface of the particles. The second peak (II) is generated by the beginning of melting. At this point, the material reaches a state without empty spaces among the grains and keeps melting, including in the interface between the compacted material and the hot metallic surface. Thus, the interval between the load point and the melting point is defined as the melting time.

According to Table 2, which summarizes the data of the graph in Fig. 2, it can be observed that the values for all formulation of time and torque have been modified, although the temperature remained constant, which means that the formulations that plasticized faster, do not present degradation trend.
It could be observed that the gelation of the PVC compound reduced with the addition of nanoparticles (F3-5N, F410N e F6-5NM) regarding to addition of micro- $\mathrm{CaCO}_{3}$ and the impact modifier. Regarding to the increase of the percentage of nano- $\mathrm{CaCO}_{3}$ in the PVC compound it could be also observed a light reduction in the gelation time and torque increasing. This behavior is due to the increase of the friction force, which accelerates the plasticization. The compound with simultaneously nano and micro- $\mathrm{CaCO}_{3}$ addition (F6-5NM) showed higher gelation peak of the compound, requesting more torque to start the plasticization and a shorter gelation interval. In this way, the result indicates that mixing two granulometries results in an early plasticization of PVC compound. This behavior is considered a good industrial practice, because besides assuring that the resin grains added are well melted avoiding defects in the PVC matrix, results in production gain. In a production cycle, polymers that melt faster generate gain in the parts production cycle/h, which can generate a productive increase.

The compound added with the impact modifier and micro- $\mathrm{CaCO}_{3}$ (F5-MOD) indicates that the PVC grains and additives fusion do not happen homogeneously, having a gelation time longer than compounds with nano- $\mathrm{CaCO}_{3}$ addiction.

\subsection{Microstructural Analysis}

The micrographs from the impact fractured surface are shown in Fig. 3 and could be observe that the distribution of $\mathrm{CaCO}_{3}$ in the PVC matrix happens in a way that, the formulations has micro- $\mathrm{CaCO}_{3}$ that has dispersed particles of irregular shape, different size and agglomerate in some areas, although there is a good dispersion of the particles in the matrix surface. And, for formulations with nano- $\mathrm{CaCO}_{3}$, the particles are spherical and there is also a variation in the granulometric distribution, not being possible to see agglomeration due to the SEM range. For both granulometries there is variation in the particles size even for the nano- $\mathrm{CaCO}_{3}$ samples.

For formulations 3 and 4 that contain $\mathrm{CaCO}_{3}$ nanoparticles it was also performed EDS to confirm the chemical structure of the particle. The test can be seen at Fig. 4 and 5 which confirm that the brighter points in the image are calcium carbonate.

Table 2. Gelation data of the PVC compounds with micro and nano- $\mathrm{CaCO}_{3}$.

\begin{tabular}{lccc}
\hline Formulation & Time $(\mathrm{min})$ & Torque $(\mathrm{Nm})$ & Temperature $\left({ }^{\circ} \mathrm{C}\right)$ \\
\hline F 1-5M & 0.74 & 25.6 & 152 \\
F 2-10M & 0.76 & 21.7 & 153 \\
F 3-5N & 0.69 & 29.1 & 153 \\
F 4-10N & 0.66 & 28.9 & 154 \\
F 5-MOD & 0.73 & 26.5 & 151 \\
F 6-5NM & 0.69 & 34.1 & 154 \\
\hline
\end{tabular}




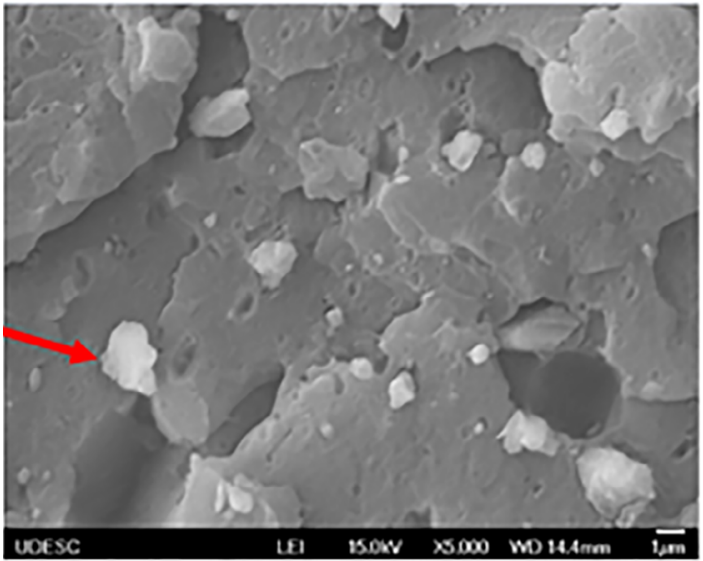

(a)

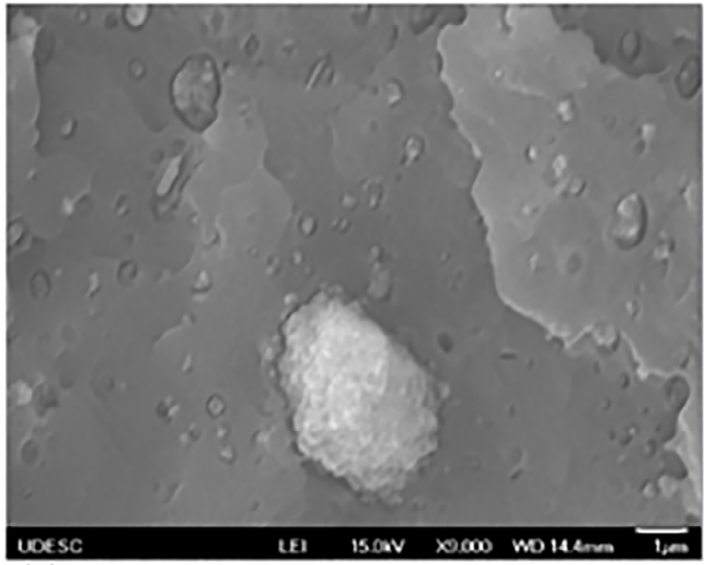

(c)

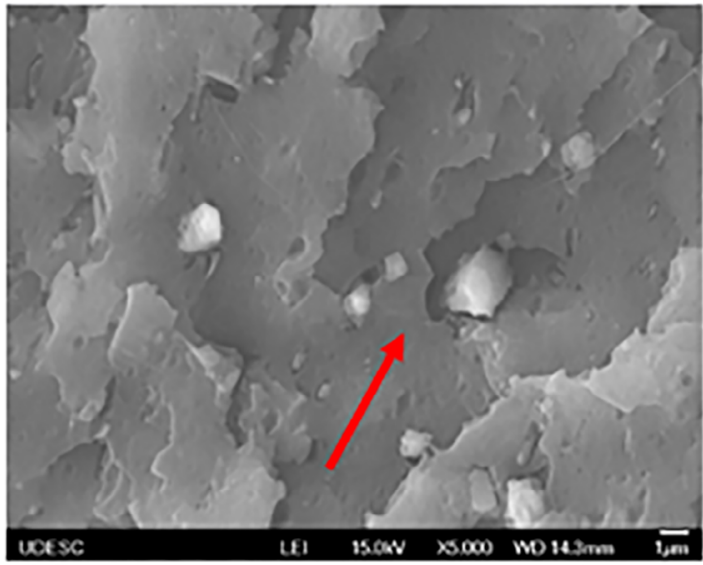

(e)

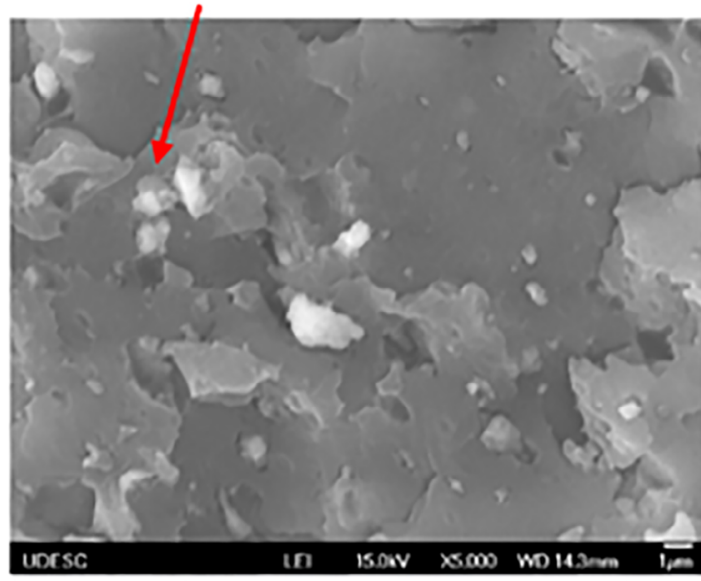

(b)

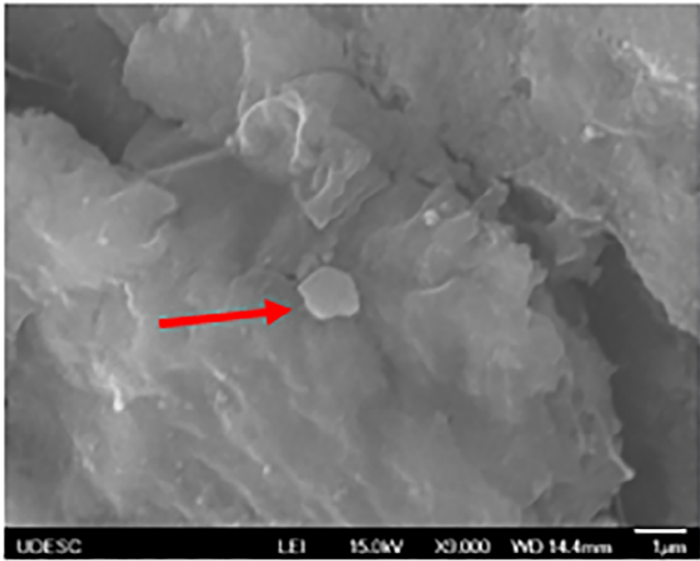

(d)

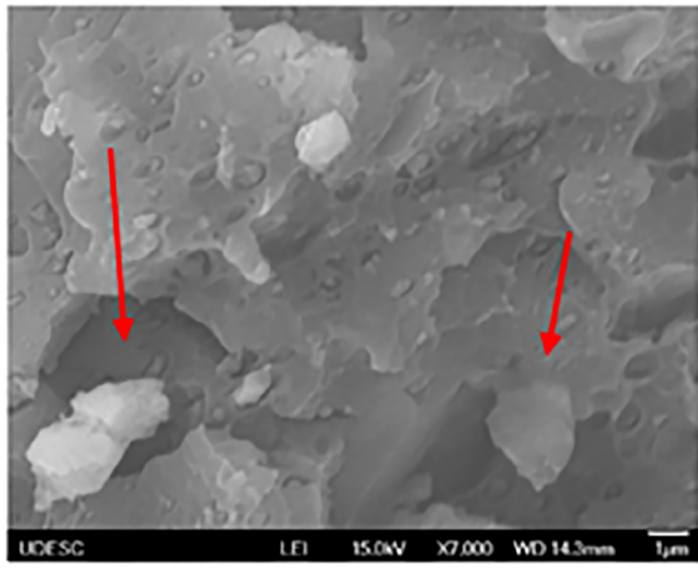

(f)

Figure 3. Micrographs of fractures of formulations obtained by SEM: a) F1-5M 5000x b) F2-10M 5000x c) F3-5N 9000x d) F4-10N 9000x e) F5-MOD 5000x and f) F6-5NM 7000x.

Fig. 6 shows micrographs of the PVC with micro and nano- $\mathrm{CaCO}_{3}$. The formulation F1-5M, F2-10M and F5-5MOD with darker color, show the presence of micro$\mathrm{CaCO}_{3}$ in regular shape (rhombohedric). The formulations F3-5N e F4-10N show the nano- $\mathrm{CaCO}_{3}$ in spherical shape, with good size homogeneity, but a high level of particles agglomeration. The formulation F6-5NM has both micro and nanoparticles, irregular and nanospherical. The presence of some agglomerates is consistent with the viscoelastic effect seen in the sample analyses by DMA. 

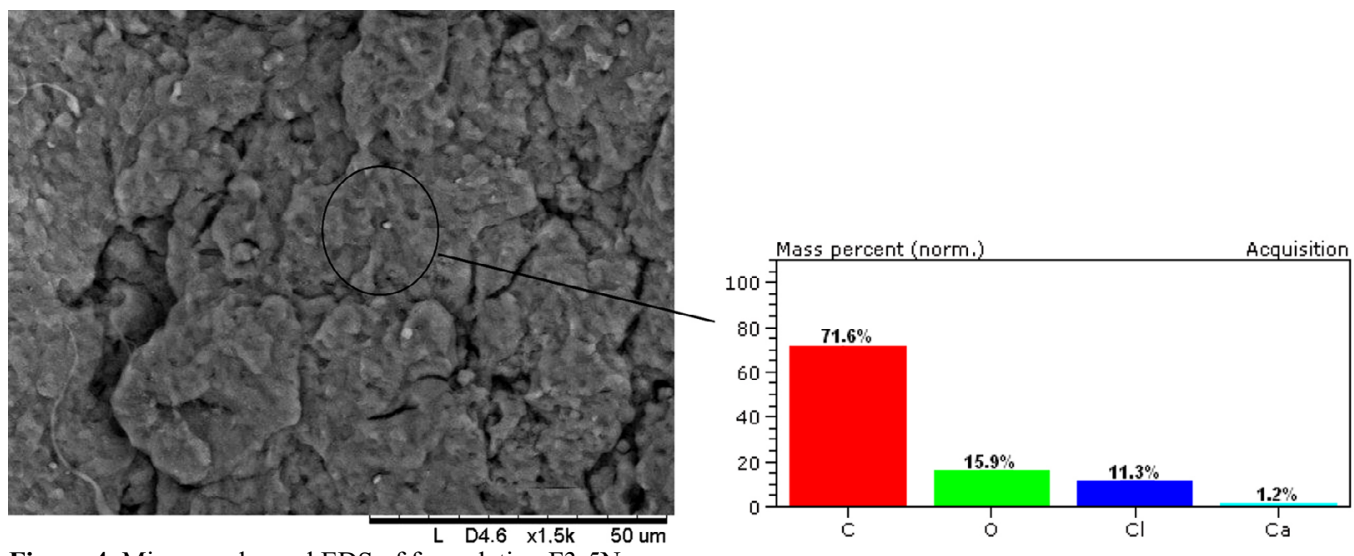

Figure 4. Micrography and EDS of formulation F3-5N.
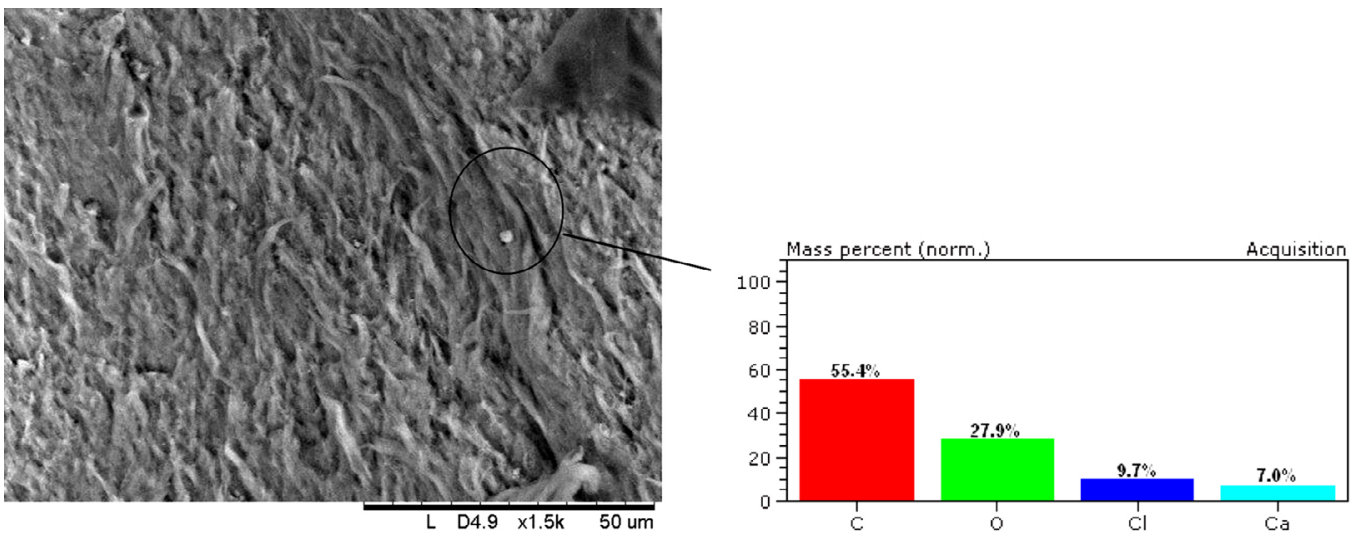

Figure 5. Micrography and EDS of formulation F4-10N.
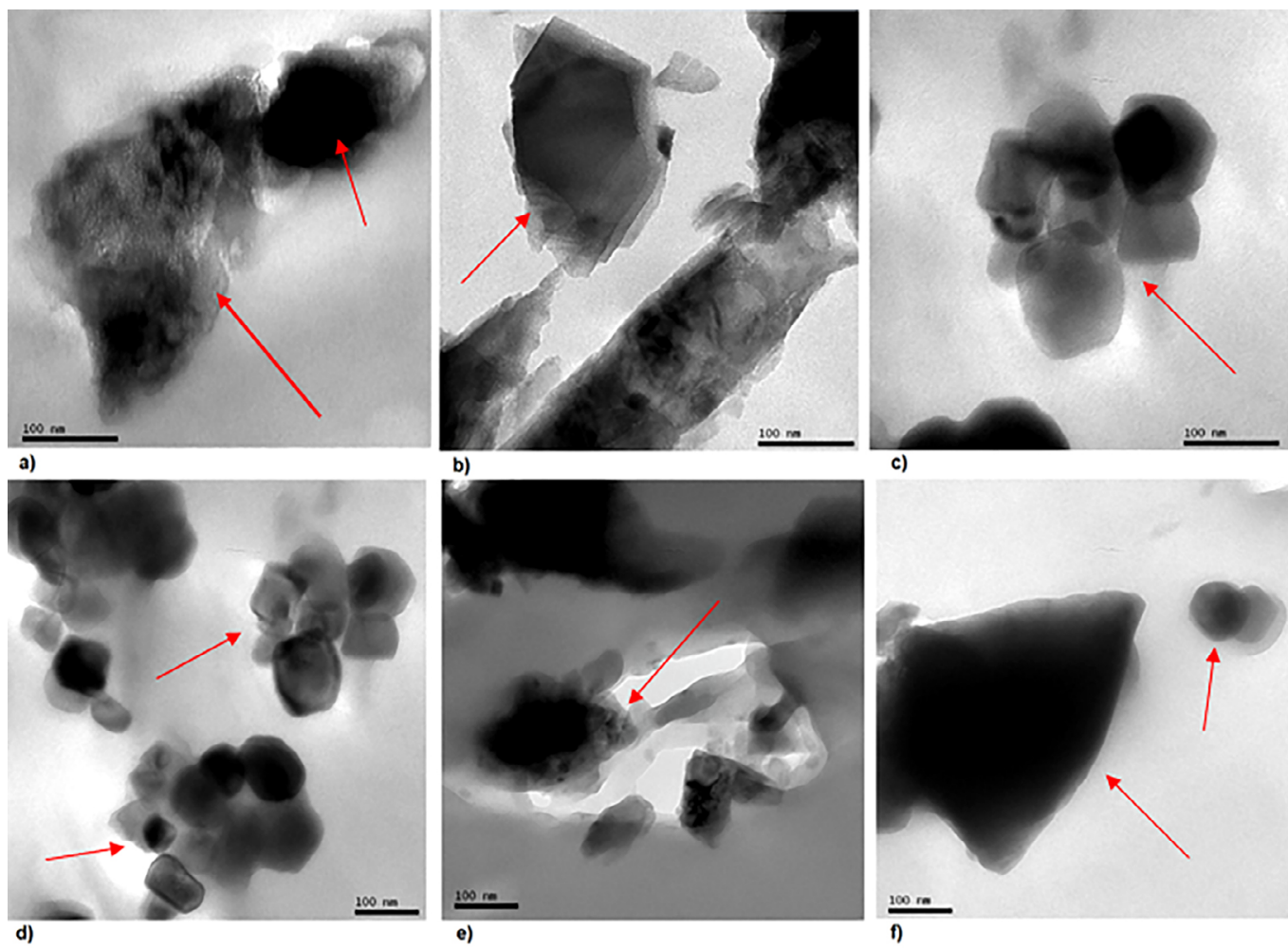
e)

Figure 6. Micrographs obtained through transmission electron microscopy of formulations a) F1-5M b) F2-10M c) F3-5N d) F4-10N d) F5-5MOD e) F6-5NM. 
Wu et al. (2004) ${ }^{4}$ shows an analysis with regard TEM micrographs obtained from PVC with nano- $\mathrm{CaCO}_{3}$ called binary nanocomposite, where it is observed that most of the nano- $\mathrm{CaCO}_{3}$ compounds were dispersed as primary particles while nanoparticles aggregate. However, more aggregates were found for binary nanocomposites when a massive percentage of nano- $\mathrm{CaCO}_{3}$ is increased. Pretty reasonable, considering that when a high concentration of nano- $\mathrm{CaCO}_{3}$ occurred, the interparticle distance was short. The authors also mentioned tests of nano- $\mathrm{CaCO}_{3}$ compounds with impact modifier of chlorinated polyethylene, called ternary compounds and observed a darker color for the formulation with impact modifier, which showed dispersion similar to other samples. Quan et al. (2007) ${ }^{9}$ also observed troubles in obtaining particles with well dispersed load, due to the ease agglomeration, he highlighted that there is the need of a dispersion process of the $\mathrm{CaCO}_{3}$ nanoparticle.

\subsection{Thermal Properties}

The results obtained in the DSC test are showed in Fig. 7 and in Table 3 for PVC compounds with addition of nano and microparticles. Through these results is possible to evaluate the degree of gelation of the PVC compounds and the influence of the addition of particles at PVC glass transition temperature $\left(\mathrm{T}_{\mathrm{g}}\right)$.

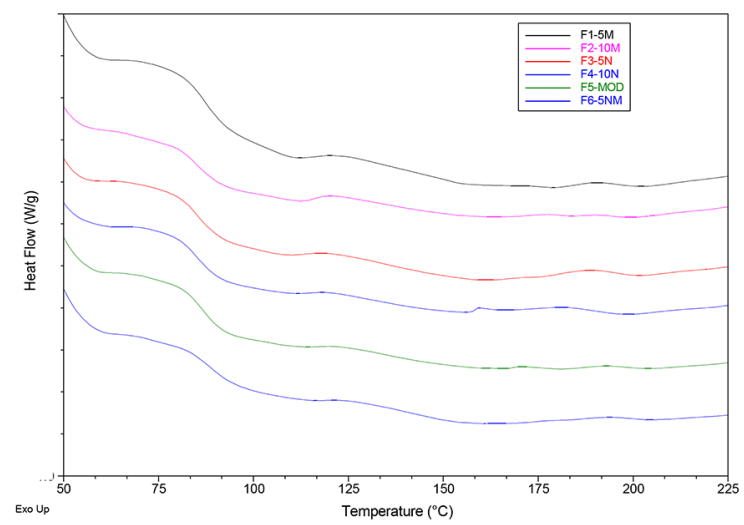

Figure 7. DSC curves for the PVC formulations with micro and nano- $\mathrm{CaCO}_{3}$.
According to Fig. 8 and Tab. 3 which presents the degree of gelation of the formulations, calculated according to Equation 1, the PVC compounds with the simultaneously addition of nano and microparticles (F6-5NM) present a higher degree of gelation ( $89 \%)$ related to compound F1$5 \mathrm{M}$, pointing out a possible synergy among different sizes of added particles.

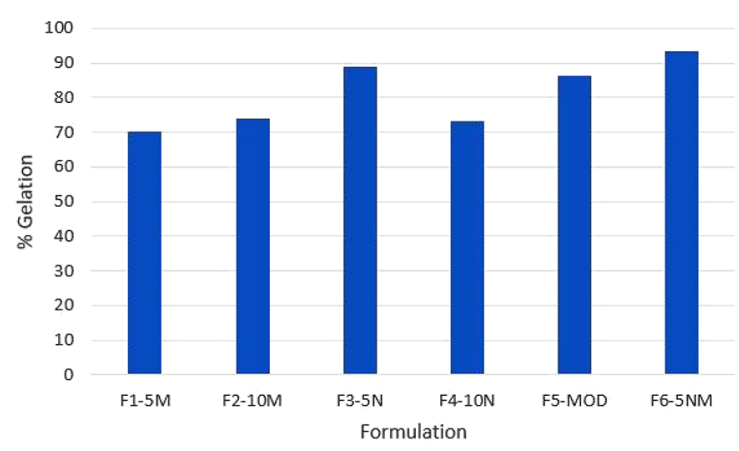

Figure 8. Degree of gelation of formulations F1-5M, F2-10M, F3-5N, F4-10N, F5-MOD, and F5-5NM.

These results corroborate with the results in Fig. 2 showed previously, which presented the highest peak of compounds gelation, highest torque to start the plasticizing and a shorter gelation interval. This fact can be due the nano- $\mathrm{CaCO}_{3}$ particles accelerate the plasticizing process. The nanoparticles addition seems to trend to increase the degree of gelation, except the compound added with 10 PCR of nano- $\mathrm{CaCO}_{3}(\mathrm{~F} 4-10 \mathrm{~N})$. The behavior of the F4-10N compound can be due to the excess quantities of nano- $\mathrm{CaCO}_{3}$ that can agglomerate and difficult the PVC resin particles plasticizing. Particles with high diameters hinder the plasticizing and gelation of $\mathrm{PVC}$, as well as non-dispersed $\mathrm{CaCO}_{3}$ particles in the $\mathrm{PVC}$ matrix. The compound added with impact modifier (F5-MOD) showed an expressive degree of gelation $(86 \%)$, not corroborating the results presented in Fig. 2. This behavior can be ascribed to the chlorinated impact modifiers and acrylics modifiers increase the degree of gelation as they act as flow accelerators, due to their chemical composition.

Table 3. Data obtained through DSC of the PVC formulations with micro and nano- $\mathrm{CaCO}_{3}$.

\begin{tabular}{lcccc}
\hline Formulation & Degree of gelation $(\%)$ & $\Delta \mathrm{H}_{\mathrm{a}}(\mathrm{J} / \mathrm{g})$ & $\Delta \mathrm{H}_{\mathrm{b}}(\mathrm{J} / \mathrm{g})$ & $\mathrm{T}_{\mathrm{g}}{ }^{\circ} \mathrm{C}$ \\
\hline F1-5M & 70.05 & 1.555 & 0.6647 & 88.3 \\
F2-10M & 74.11 & 1.615 & 0.5642 & 86.5 \\
F3-5N & 88.99 & 4.455 & 0.5513 & 84.8 \\
F4-10N & 73.41 & 2.682 & 0.9715 & 84.8 \\
F5-MOD & 86.32 & 3.021 & 0.4789 & 86.5 \\
F6-5NM & 93.44 & 4.018 & 0.2823 & 84.0 \\
\hline
\end{tabular}


The glass transition values for the compound with nano$\mathrm{CaCO}_{3}$ particles showed a decrease related to the compound with micro- $\mathrm{CaCO}_{3}$ particles as well as no variation with increasing the mass fraction of nano- $\mathrm{CaCO}_{3}$ particles. This behavior was not in accordance as mentioned in another authors $^{10,11}$. In other words, for this study the presence of the nano and micro- $\mathrm{CaCO}_{3}$ particles in the $\mathrm{PVC}$ matrix it seems not hindered the mobility of the segments of polymer chains, so chain segments of the polymer.

Thermogravimetric curves (TG) and the $1^{\text {st }}$ derivative of the thermogravimetric curves (DTG) for formulations of PVC compound with micro and nano- $\mathrm{CaCO}_{3}$ are shown in Fig. 9 and Tab. 4 shows the results of all compounds.
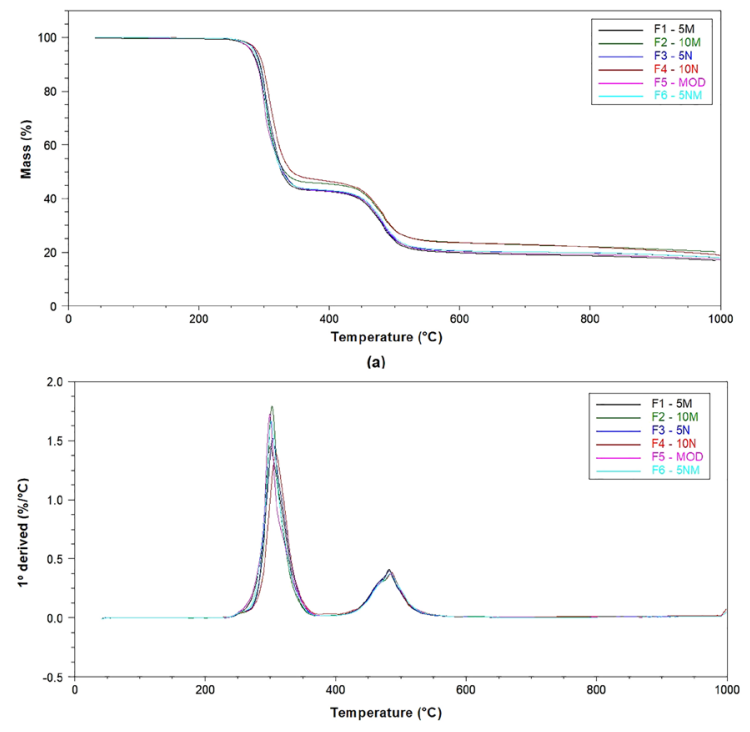

(b)

Figure 9. Curves of (a) TG and (b) DTG of PVC formulations with micro and nano- $\mathrm{CaCO}_{3}$ obtained through TGA.

The results show the presence of two stages of degradation in the PVC compounds. The $1^{\text {st }}$ stage occurs between 250 and $350{ }^{\circ} \mathrm{C}$, with mass loss percentages varying from 54 to $57 \%$, which can be attributed to the phenomenon of dehydrochlorination of PVC matrix. The $2^{\text {nd }}$ stage occurs between 420 and $520{ }^{\circ} \mathrm{C}$, with mass loss percentage varying from 25 to $28 \%$, which could correspond to the pyrolysis of the polyene sequence formed during the $1^{\text {th }}$ stage.
The presence of these two stages of degradation in that range of temperature, are in agreement with literature ${ }^{10,12}$. After the end of the analysis a residue remained that varied from 17 to $20 \%$ related to the PVC compounds studied.

An increase of $1.74 \%$ at $\mathrm{T}_{\text {onset }}$ was observed with the increase of content of micro- $\mathrm{CaCO}_{3}$ particles in the PVC compound. The PVC compound with nano- $\mathrm{CaCO}_{3}$ showed an increment of $1 \%$ at $\mathrm{T}_{\text {onset }}$ passing from formulation $\mathrm{F} 3-5 \mathrm{~N}$ to formulation F4-10N. For the same content of particles in 5 PCR, for micro and nano- $\mathrm{CaCO}_{3}$ particles, the $\mathrm{T}_{\text {onset }}$ raised $1 \%$, indicating that the nano- $\mathrm{CaCO}_{3} \mathrm{PVC}$ compounds are slightly thermally more stable than their respective micro $\mathrm{CaCO}_{3}$ PVC compounds. The formulation F5-MOD maintained the same $\mathrm{T}_{\text {onset }}$ of $286^{\circ} \mathrm{C}$ as F1-5M, i.e., the impact modifier has not influenced the thermal stability. While F6-5NM showed $\mathrm{T}_{\text {onset }}$ raise compared to F1-5M, so that, it is possible improve the thermal stability also mixing both particle sizes in the same formulation. All samples presented the same tendency with temperature (same thermograms profile) and thermal stability as well the residue around $18 \%$, what were similar to that observed for other PVC/ $\mathrm{CaCO}_{3}$ composites ${ }^{11}$. An study evaluated the TG curves to PVC matrix with micro and nano- $\mathrm{CaCO}_{3}{ }^{1}$, they observed that $\mathrm{T}_{\text {onset }}$ values were superior to formulations containing nano- $\mathrm{CaCO}_{3}$, due to the larger surface area of inorganic nanoparticles in contact with the PVC heat, protecting the PVC matrix against heat and delaying the thermal degradation.

The results from the dynamic mechanical analysis (DMA), through module storage curves $\left(E^{\prime} \times \mathrm{T}\right)$ and the loss module (E" $\mathrm{x}$ T) are shown in Fig. 10 and Tab. 5. Analyzing the results, it could be seen that the $T_{g}$, values, obtained from the maximum peak point of Tan $\delta$, have not suffered modification with different particle size and mass fraction of micro and nano- $\mathrm{CaCO}_{3}$ particles.

Table 5. Glass transition temperature for formulations with micro and nano- $\mathrm{CaCO}_{3}$ measured through DMA from the loss module (E”).

\begin{tabular}{lc}
\hline Formulation & $\operatorname{Tg}\left({ }^{\circ} \mathrm{C}\right)$ \\
\hline F1-5M & 78 \\
F2-10M & 79 \\
F3-5N & 79 \\
F4-10N & 79 \\
F5-MOD & 79 \\
F6-5NM & 79 \\
\hline
\end{tabular}

Table 4. Data obtained through TGA of the PVC formulations with micro and nano- $\mathrm{CaCO}_{3}$.

\begin{tabular}{|c|c|c|c|c|c|c|c|}
\hline Formulation & $\mathrm{T}_{\text {onset } 1}\left({ }^{\circ} \mathrm{C}\right)$ & $\mathrm{T}_{\mathrm{d} 1}\left({ }^{\circ} \mathrm{C}\right)$ & $\%$ mass loss 1 & $\mathrm{~T}_{\text {onset } 2}\left({ }^{\circ} \mathrm{C}\right)$ & $\mathrm{T}_{\mathrm{d} 2}\left({ }^{\circ} \mathrm{C}\right)$ & $\%$ mass loss 2 & $\%$ residue \\
\hline F1-5M & 286 & 299 & 57 & 452 & 482 & 26 & 17 \\
\hline F2-10M & 291 & 302 & 54 & 452 & 484 & 25 & 20 \\
\hline F3-5N & 289 & 304 & 57 & 452 & 483 & 25 & 18 \\
\hline F4-10N & 292 & 308 & 54 & 453 & 486 & 28 & 19 \\
\hline F5-MOD & 286 & 299 & 57 & 453 & 484 & 25 & 17 \\
\hline F6-5NM & 288 & 301 & 57 & 452 & 484 & 25 & 18 \\
\hline
\end{tabular}



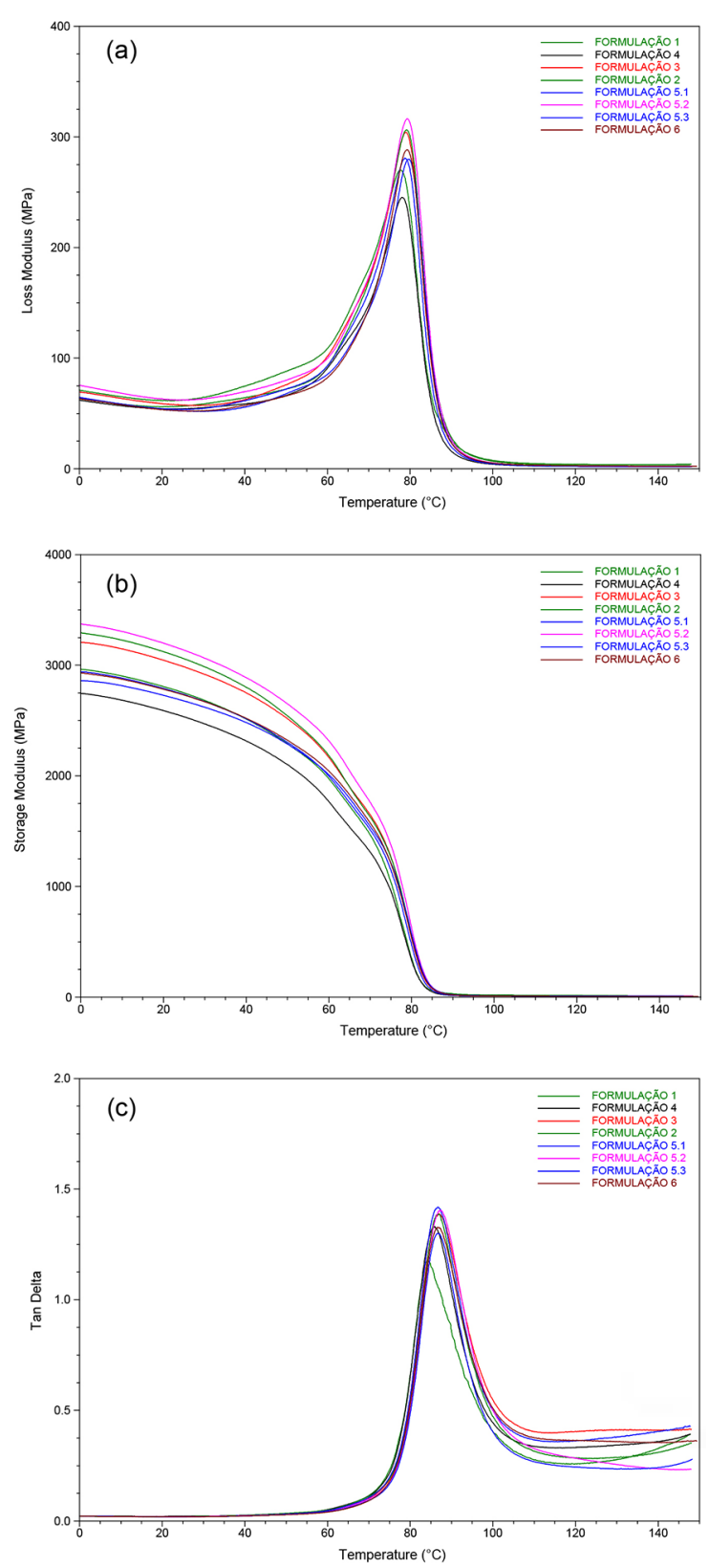

Figure 10. DMA curves for PVC formulations: (a) E"xT and (b) E'xT (c) Tan delta.

In relation to the storage module, it is possible to observe that formulations F1-5M, F2-10M, and F5-MOD have a storage module slightly superior when compared to formulations nano F3-5N, F4-10N and F6-5NM.

This same behavior was observed in another study ${ }^{1}$, where micro- $\mathrm{CaCO}_{3}$ samples showed modules slightly superior regarding nanocomposites and pure PVC in the glass region. In addition, the storage module magnitude is higher increasing the micro- $\mathrm{CaCO}_{3}$ content in the same (glass region).
In general, the nanocomposites not shown significative variation in the storage module, as well in $\mathrm{T}_{\mathrm{g}}$. This unexpected viscoelastic behavior was again responsible for the nonuniform distribution of nanoparticles and for the development of agglomerates, leading to non-homogeneous interaction between the organic matrix and the inorganic filler.

\subsection{Mechanical Properties}

The results of the impact resistance obtained for micro and nano- $\mathrm{CaCO}_{3}$ PVC compounds are shown in Fig. 11. The micro- $\mathrm{CaCO}_{3}$ PVC compounds showed an increase at impact resistance with the increase of particles mass fraction. The same tendency was observed for the nano$\mathrm{CaCO}_{3}$ PVC compounds. The impact resistance values for nanoparticles PVC compound are higher than the values of the microparticles PVC compound. This behavior can be attributed to the nanometric particles large capacity for absorbing energy.

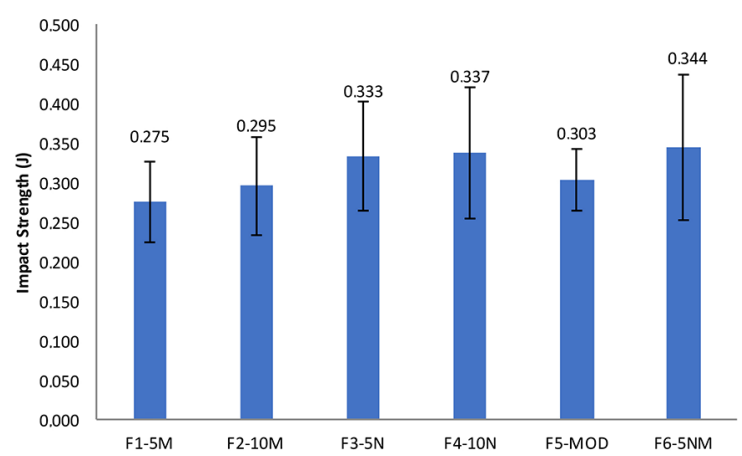

Figure 11. Impact resistance values of the PVC compounds with micro and nano- $\mathrm{CaCO}_{3}$.

A trend for impact resistance to be slightly higher in when compared to the micro- $\mathrm{CaCO}_{3}$ PVC compound was observed for F5-MOD compound. However, a lower impact resistance value compared to nano- $\mathrm{CaCO}_{3} \mathrm{PVC}$ compound can be noticed. The F6-5NM compound which has both size particles and mass fraction showed a slightly superior trend than all other compounds, this fact can be evidence of synergy among the particles. According to the literature ${ }^{13}$, the nano- $\mathrm{CaCO}_{3}$ particles can act as locations of stress concentration that could lead to cavitations in the particle's matrix limits during the strain. The cavitations can release the polymer restriction and triggering plastic deformation of the matrix that leads to higher tenacity.

The results of mechanical properties of tension for micro and nano- $\mathrm{CaCO}_{3}$ PVC compounds are showed at Fig. 12 (a-c). For tensile strength, with $\mathrm{CaCO}_{3}$ increase, whether in micro or nanoscale, as slightly reduction in the values occurs, and that the average $5 \mathrm{phr}$ of $\mathrm{CaCO}_{3}$ shows values slightly similar, i.e., from this value the tensile strength trends to reduce. 


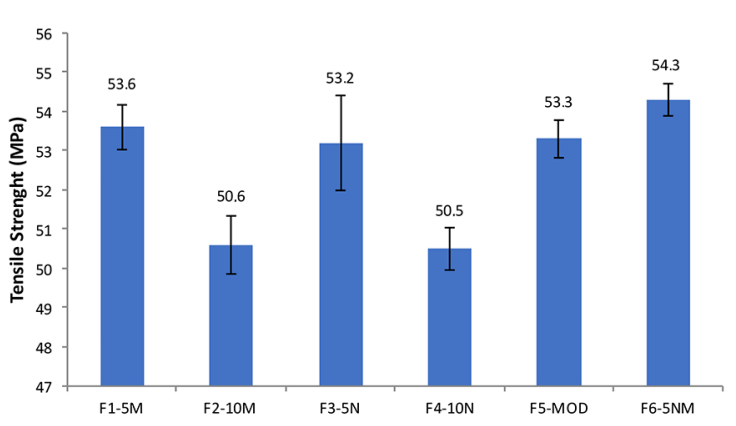

(a)

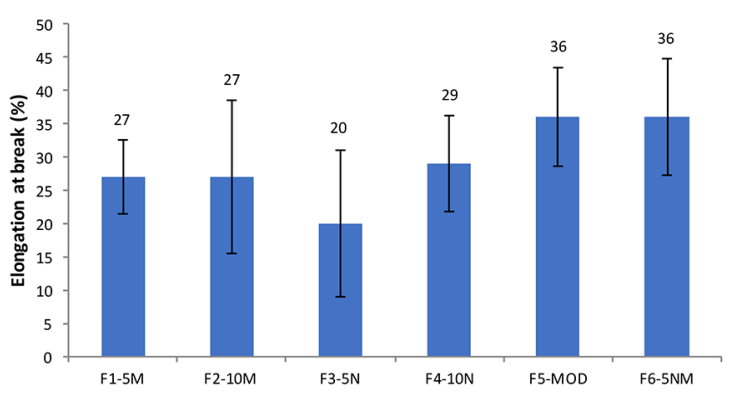

(b)

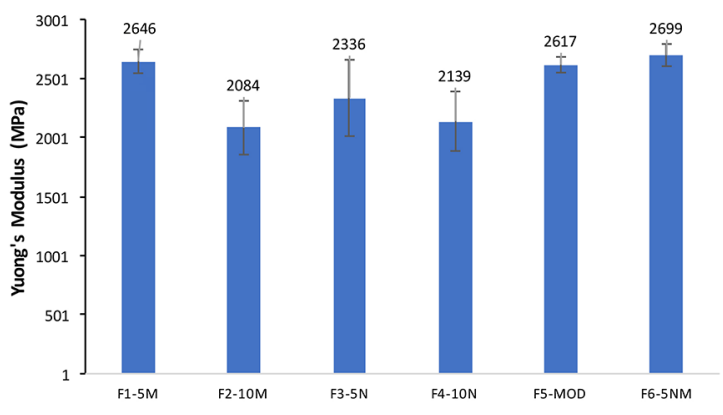

(c)

Figure 12. Results of the tensile strength testing of the micro and nano- $\mathrm{CaCO}_{3} \mathrm{PVC}$ compounds: a) Tensile strength, b) elongation at break, c) Young's modulus.

The same for formulations F5-MOD and F5-5NM that also have $5 \mathrm{phr}$ of $\mathrm{CaCO}_{3}$, i.e., values above $5 \mathrm{phr}$ trend to reduce the tensile strength. In this work the authors vary from 5 to $25 \mathrm{phr}$ in both particle sizes and obtained results about $15 \%$ at decrease in tensile strength ${ }^{14}$. A similar result was registered by Guermazi et al. (2016) ${ }^{11}$.

According to the literature ${ }^{8}$, the average of elongation at break for PVC compounds with micrometric $\mathrm{CaCO}_{3}$ is 2 to $40 \%$. The elongation at break results in this study presented a standard deviation quite different for the 6 formulations. However, formulations F1-5M and F2-10M remained with approximated values, showing that in micro particles the load increase did not result in less deformation. Comparing the formulations nano F3-5N and F4-10N it could be observed a trend to a value slightly higher with the $\mathrm{CaCO}_{3}$ increase, while F5-MOD and F6-5NM remain with the same values.
That is, the stiffening effect of the PVC matrix was only conferred due to the nanoparticles, which with their increase in mass tends to increase the tensile strength. The inclusion of modifier in F5-MOD and the mixing of the two $\mathrm{CaCO}_{3}$ particle sizes in F6-5NM gave greater flexibility to the PVC matrix in relation to F1, F2, F3, and F4.

For Young's modulus, the values decreased by about $21 \%$ with the mass percentage increase, of the load compared to formulations F1-5M and F2, while the values reduced around $8.5 \%$ with the mass percentage comparing the formulations $\mathrm{F} 3$ and $\mathrm{F} 4$.

The mass values of $5 \mathrm{phr}$ remain in approximate values, F5-MOD varied $1 \%$ against F1-5M and against F6-5NM. The formulations F5-MOD, F6-5NM, and F1-5M have the highest Young's modulus, consequently, the higher stiffness. This behavior was in agreement with the literature ${ }^{11}$, that suggest that the addition of $\mathrm{CaCO}$ fillers leads to the enhancement of the rigidity of the material. Once that the presence of fillers in the PVC matrix offers resistance to the segmental movement of the polymer chains on the application of the tensile stress which can lead to enhancement in modulus.

Wu et al. (2004) ${ }^{4}$ observed that PVC nanocomposites with nano- $-\mathrm{CaCO}_{3}$, with a mass relation of $95 / 5$ showed a tensile strength slightly higher than pure PVC, which showed that the nano- $\mathrm{CaCO}_{3}$ particles reinforced the strength in the PVC matrix. However, an additional increase in the content of nano- $\mathrm{CaCO}_{3}$ resulted in a reduction in the tensile strength. It can be a result of the poor combination of the polymer with reinforcement. On the other hand, the elongation at break kept a continuous increase with the increase in the content of nano- $\mathrm{CaCO}_{3}$. It could be explained by the increase of the matrix deformation caused by the energy that dissipates at the toughening.

That is, according to the SEM and TEM tests in the present study, the particles cause a reduction of the tensile strength values and elongation at break, which did not happened in the values of formulation F6-5NM, and again it was evident that for formulations without pre-dispersion or coupling agents, values above $2.5 \mathrm{phr}$ cause reduction in the tensile values.

This effect of decreased tensile strength for formulations higher than 2.5 PCR is due to the poor dispersion of $\mathrm{CaCO}_{3}$ particles in the PVC matrix, as shown in Fig. 5 and Fig. 6 , which show the agglomerated particles, which hinder PVC plasticization and consequently reduce its mechanical resistance. The matrix regions comprising agglomerated particles become weakening points upon mechanical stress of the respective PVC matrix. For this reason, it is necessary to reduce their weight percent per formulation, or to use methods for dispersing and incorporating $\mathrm{CaCO}_{3}$ particles into $\mathrm{PVC}$, and mixing nano and micro- $\mathrm{CaCO}_{3}$ particles may have somehow balanced their particle size distribution curve, which consequently, improves the properties of the polymeric matrix to which it will be incorporated. 


\section{Conclusions}

Regarding to the compound preparation, it was possible incorporate the nano- $\mathrm{CaCO}_{3}$ using a standard equipment of micro- $\mathrm{CaCO}_{3}$ mixing, using the same parameters. The compound processed in the rheometer showed similar rheologic curves, but the sample F6-5NM stood out regarding plasticizing and proved itself faster than in other samples. This was also seen in the torque, that varied around $36 \%$ among the samples, fact attributed to the torque superior peak, as more plasticized the material more torque is required in the equipment. This is reflected in the energy cost that can be higher due to the greater effort to rotate the spindle motor of an extruder. Higher torques due to the high plasticization can lead to polymer degradation, but the temperature remains constant, which leads to a good safety range even with F6-5NM plasticizing faster.

The tensile strength and impact resistance tests specimens did not show results substantially different when the loads granulometries were compared. However, the sample F6$5 \mathrm{NM}$ showed a result slightly superior related to the others. It can be related to the poor adherence of the nanoload to the matrix in amounts higher than $2.5 \mathrm{phr}$, it would be necessary to modify the mixing parameters, to assure the maximum load incorporation. For the Young's modulus, the formulations F3-5N and F4-10N showed inferior results than other formulations. For this assay, the formulation F6-5NM features superior values along with the formulation F1-5M. In this way, through mechanical testing, it was observed a trend to obtain synergy between $\mathrm{CaCO}_{3}$ and the PVC matrix where the load has a mix with two particle sizes chosen for this study.

The SEM analysis showed that micro- $\mathrm{CaCO}_{3}$ particles have regular shape, a poor particle sizes distribution, a good dispersion and a trend to agglomerate according to the massive percentage, in nanoparticles it was possible observe a spherical shape.

The TEM showed that formulations with micro- $\mathrm{CaCO}_{3}$ have particles of irregular shapes with different sizes and light agglomeration. The formulations with nano- $\mathrm{CaCO}_{3}$ showed spherical particles well defined, with good granulometric distribution, but high particles agglomeration. In F5-MOD there was the presence of the impact modifier, while in sample F6-5NM large and irregular and small and round particles with low agglomeration could be seen.

In the thermal analysis, $\mathrm{T}_{\mathrm{g}}$ was not modified for micro and nano- $\mathrm{CaCO}_{3}$. The samples showed different gelation according to the granulometry and percentage, considering that nano-formulations showed more gelation. The thermal stability $\left(\mathrm{T}_{\text {onset }}\right)$ also increased with the massive increase of micro and nano- $\mathrm{CaCO}_{3}$.

Finally, with this study it was evaluated if it is possible use nano- $\mathrm{CaCO}_{3}$ in the industry e and if there is a trend to improve the mechanical strength, processability and the cost-effectiveness, using polymers incorporation and transformation equipment already used in the market.

\section{Acknowledgments}

To Micron-ita for the support to the Project and the donation of the nano calcium carbonate and to Braskem for the tests performed.

\section{References}

1. Patil CB, Kapadi UR, Hundiwale DG, Mahulikar PP. Preparation and characterization of poly(vinyl chloride) calcium carbonate nanocomposites via melt intercalation. Journal of Materials Science. 2009;44(12):3118-3124. Available from: https://doi. org/10.1007/s10853-009-3414-y

2. Ari GA, Aydin I. Rheological and fusion behaviors of pve microand nano-composites evaluated from torque rheometer data. Journal of Vinyl and Additive Technology. 2010;16(4):223-228. Available from: https://doi.org/10.1002/vnl.20241

3. Poveda PS, Silva LA. O uso de nano carbonato de cálcio como extensor de pigmento branco a base de dióxido de titânio aplicado em polietileno. Anais do $11^{\circ}$ Congresso Brasileiro de Polímeros; 2011 out 16-20; Campos do Jordão (SP): CBPOL; 2011.

4. Wu D, Wang X, Song Y, Jin R. Nanocomposites of poly (vinyl chloride) and nanometric calcium carbonate particles: effects of chlorinated polyethylene on mechanical properties, morphology, and rheology. Journal of Applied Polymer Science. 2004;92(4):2714-2723. Available from: https://doi. org/10.1002/app.20295

5. Sun S, Li C, Zhang L, Du HL, Burnell-Gray JS. Interfacial structures and mechanical properties of PVC composites reinforced by $\mathrm{CaCO}_{3}$ with different particle sizes and surface treatments. Polymer International. 2006;55(2):158-164. Available from: https://doi.org/10.1002/pi.1932

6. Kemal I, Whittle A, Burford R, Vodenitcharova T, Hoffman M. toughening of unmodified polyvinylchloride through the addition of nanoparticulate calcium carbonate and titanate coupling agent. Journal of Applied Polymer Science. 2013;127(3):2339-2353. Available from: https://doi.org/10.1002/app.37774

7. Jazi SHS, Esfahany MN, Bagheri R. Investigation of the addition of nano- $\mathrm{CaCO}_{3}$ at dry mixing or onset of fusion on the dispersion, torque, and mechanical properties of compounded PVC. Journal of Vinyl and Additive Technology. 2012;18(3):153-160. Available from: https://doi.org/10.1002/vnl.20317

8. Nunes LR, Rodolfo Junior A, Ormanji W. Tecnologia do PVC. $2^{\mathrm{a}}$ ed. São Paulo: Braskem; 2006.

9. Quan Y, Yang M, Liang T, Yan Q, Liu D, Jin R. Effects of the reinforcement and toughening of acrylate resin/CaCO nanoparticles on rigid poly(vinyl chloride). Journal of Applied Polymer Science. 2007;103(6):3940-3949. Available from: https://doi.org/10.1002/app.24464

10. Jiang Z, Wang J, Ge R, Wu C. The effects of surface modification of ground calcium carbonate powdery fillers on the properties of PVC. Polymer Bulletin. 2018;75(3):1123-1139. Available from: https://doi.org/10.1007/s00289-017-2081-4 
11. Guermazi N, Haddar N, Elleuch K, Ayedi HF. Effect of filler addition and weathering conditions on the performance of PVC/ $\mathrm{CaCO}_{3}$ composites. Polymer Composites. 2016;37(7):2171-2183. Available from: https//doi.org/10.1002/pc.23396

12. Shimpi NG, Verma J, Mishra S. Dispersion of nano $\mathrm{CaCO}_{3}$ on PVC and its influence on mechanical and thermal properties. Journal of Composites Materials. 2009;44(2):211-219. Available from: https://doi.org/10.1177/0021998309344637
13. Chetanachan W, Sutthitavil W, Chomcheuy W. Effect of nanocalcium carbonate on the impact strength and accelerated weatherability of rigid poly(vinyl chloride)/acrylic impact modifier. Journal of Vinyl \& Additive Technology. 2011;17(2):92-97. Available from: https://doi.org/10.1002/vnl.20266

14. Chen CH, Teng CC, Su SF, Wu WC, Yang CH. Effects of microscale calcium carbonate and nanoscale calcium carbonate on the fusion, thermal, and mechanical characterizations of rigid poly(vinyl chloride)/calcium carbonate composites. Journal of Polymer Science Part B: Polymer Physics. 2005;44(2):451-460. Available from: https://doi.org/10.1002/polb.20721 